\title{
Study of Arrhythmias in Acute Myocardial Infarction
}

\author{
Nagabhushana $S^{1}$, Ranjith kumar $G^{2}$, Ranganatha $M^{3}$, Virupakshappa ${ }^{4}$ \\ ${ }^{1}$ Dr Nagabhushana S, Assistant Professor, Department of General Medicine, Shimoga Institute of Medical Sciences \\ (SIMS), Shimoga, ${ }^{2}$ Dr Ranjith kumar GK, Junior Resident, Department of General Medicine, Shimoga Institute of \\ Medical Sciences (SIMS), Shimoga, ${ }^{3}$ Dr Ranganatha M, Assistant Professor, Department of General Medicine, Shimoga \\ Institute of Medical Sciences (SIMS), Shimoga, ${ }^{4}$ Dr Virupakshappa, Professor \& HOD, Department of General \\ Medicine, Shimoga Institute of Medical Sciences (SIMS), Shimoga, Karnataka, India
}

Address for correspondence: Dr Nagabhushana S, Email: sn_bhushan@yahoo.co.in

\begin{abstract}
Background: Acute Coronary Syndrome (ACS) represents a Global epidemic. There is not much documented evidence regarding the profile of arrhythmias in the present population of Shimoga. Hence the purpose of this study is to evaluate the incidence and profile of cardiac Arrhythmias in AMI in the first week of hospitalization in a tertiary care hospital in shimoga, karnataka. Material and Methods: 100 patients of Acute Myocardial Infarction (AMI) admitted to ICCU of Mc Gann Hospital from April 2015 to June 2015 were studied. The first electrocardiogram (ECG) was recorded at the earliest after admission, subsequently at four hourly interval on first day, daily for the duration of stay and as \& when needed, cardiac enzymes and 2D echocardiography were done to confirm MI. Result: The mean age was $52.914 \pm 13.19$ years with male to female ratio being 2.9:1. Incidence of arrhythmias was 89\%, majority (67\%) of arrhythmias occurred during first 24 hours. Sinus tachycardia (48\%), ventricular premature beats (VPCs) (24\%), Sinus bradycardia (22\%) and atrial premature complexes (15\%) were common arrhythmias encountered in study. Atrioventricular blocks $(93.4 \%)$ were more common in inferior wall infarctions. Arrhythmias were documented in $90.91 \%$ of anterior wall MIs, $83.33 \%$ of inferior wall MIs and $100 \%$ of combined (anterior and inferior) MIs. Conclusion: Our observations confirmed the differences in the occurrence of arrhythmias in different setup and locality and need for individualization of management protocol in different setup.
\end{abstract}

Key words: Acute Myocardial Infarction, Arrhythmias, Sinus tachycardia, Anterior wall MI, Atrioventricular blocks.

\section{Introduction}

Acute Coronary Syndrome (ACS) represents a Global epidemic. According to the National Commission on Macro-economics and Health, there would be around 62 million patients with Coronary Artery Disease (CAD) by 2015 in India, and of these, 23 million would be younger than 40 years of age [1]. Many of these deaths are attributed to the development of arrhythmias during periods of myocardial infarction [2]. There is a view that the cascade leading to sudden death from arrhythmias can be predicted by certain interactions among structural and functional abnormalities [3]. The search for new tools for prediction, the refinement of the existing tools, and the initiation of well designed intervention trials are the steps that must be taken towards the more efficient prevention of premature deaths from arrhythmias. There is not much documented evidence regarding the profile of such Manuscript received: $1^{\text {st July } 2015}$ Reviewed: $4^{\text {th }}$ July 2015

Reviewed: $4^{-1}$ July 2015

Accepted for Publication: $27^{\mathrm{h}}$ July 2015 arrhythmias in the present population of shimoga. Hence the purpose of this study is to evaluate the incidence and profile of cardiac Arrhythmias in AMI in the first week of hospitalization in a tertiary care hospital in Shimoga, Karnataka.

\section{Materials and Methods}

This study was carried out in Intensive coronary care unit (ICCU) of Mc Gann Hospital, SIMS, Shimoga.

The material of study consisted of 100 consecutive patients of Acute Myocardial Infarction (AMI) admitted to ICCU of Mc Gann Hospital from April 2015 to June 2015.

\section{Inclusion criteria}

Patients satisfying WHO definition [4] for diagnosis of myocardial infarction were included in the study. 
Diagnosis was based in presence of the following three criteria:

1. A clinical history of ischemic type chest discomfort.

2. Changes in serially obtained electrocardiographic tracings.

3. A rise and fall of serum cardiac markers.

\section{Exclusion criteria}

1. Known case of Arrhythmogenic heart disease

2. Recurrent Myocardial infarction

3. Valvular Heart disease

A detailed history was taken in all the patients and a through physical examination was done as per the proforma.

The first electrocardiogram (ECG) was recorded at the earliest after admission and subsequently at four hourly interval on first day, daily for the duration of stay in ICCU and thereafter as per need. 12 lead ECG was recorded before and after the thrombolytic therapy.
Right ventricular leads were recorded whenever deemed necessary. Patients were mentioned for any clinical changes and ECG changes. Standard lead II was used to monitor and record rhythm disturbance; modified chest lead I(MCL 1 lead or Marriot's lead) was used whenever necessary. In addition 12 lead ECG was also recorded during occurrence of arrhythmias. ECGs were recorded on BPL Cardiart 6208 view.

The other investigations to which the patients were subjected to confirm MI are as follows:

a. Cardiac enzymes.

b. Echocardiography (2D).

Patients were kept in ICCU for 3-5 days provided no other complication was present. From ICCU they were transferred to cardiac ward and discharged after 1-2 weeks.

Localisation of MI was done by typical infarction pattern present in chest leads as per standard references available [5]

\section{Results}

100 consecutive patients of Acute Myocardial Infarction admitted to ICCU of Mc Gann Hospital, SIMS, Shimoga from April 2015 to June 2015 were studied. The following are the observations made from this study.

\section{Age Distribution}

Table 1: showing age and sex distribution

\begin{tabular}{|l|l|l|l|}
\hline \multirow{2}{*}{ Age group (in years) } & \multicolumn{2}{|l|}{ No. of patients } & \multirow{2}{*}{ Percentage (\%) } \\
\cline { 2 - 4 } & Male & 0 & \\
\hline Less than 30 & 4 & 2 & 4 \\
\hline $31-40$ & 16 & 10 & 18 \\
\hline $41-50$ & 20 & 10 & 30 \\
\hline $51-60$ & 16 & 4 & 26 \\
\hline $61-70$ & 6 & 1 & 10 \\
\hline $71-80$ & 6 & 1 & 7 \\
\hline More than 81 & 4 & $\mathbf{2 8}$ & 5 \\
\hline Total & $\mathbf{7 2}$ & $\mathbf{1 0 0}$ \\
\hline
\end{tabular}

The age of patients in this study ranged from 26 years to 84 years. Mean age was $45.61( \pm 14.16)$ yeas. Out of 100 cases, 72 were males and 28 were female. The male to female ratio was 2.9:1. 
Table 2: Showing site of Infarction

\begin{tabular}{|l|l|l|}
\hline Site of Infraction & No. of cases & Percentage \\
\hline Anterior wall MI & $\mathbf{6 6}$ & $\mathbf{6 6}$ \\
\hline Anteroseptal MI & 32 & 32 \\
\hline Lateral wall MI & 1 & 1 \\
\hline Anterior wall MI & 16 & 16 \\
\hline Extensive anterior wall MI & 17 & 17 \\
\hline Inferior wall MI & $\mathbf{3 0}$ & $\mathbf{3 0}$ \\
\hline Inferior wall MI & 18 & 18 \\
\hline Infero-lateral MI & 12 & 12 \\
\hline Combined (Anterior and inferior) MI & $\mathbf{4}$ & $\mathbf{4}$ \\
\hline
\end{tabular}

Majority (76\%) of patients were admitted within 24 hours of onset of symptoms. There were 11 cases of right ventricular infarction - 10 were associated with inferior wall MI and 1 case occurred in anterior wall MI. There were 5 cases of posterior wall MI (associated with inferior wall MI). Q waves developed in 87 cases (87\%).

Table 3: showing Incidence of arrhythmias

\begin{tabular}{|l|l|l|}
\hline Arrhythmias & No. of cases & Percentage \\
\hline Present & 89 & 89 \\
\hline Absent & 11 & 11 \\
\hline
\end{tabular}

89 patients $(89 \%)$ developed arrhythmias in one form or other.

Time of Appearance of Arrhythmias

Figure 1: showing the time of appearance of arrhythmias after admission

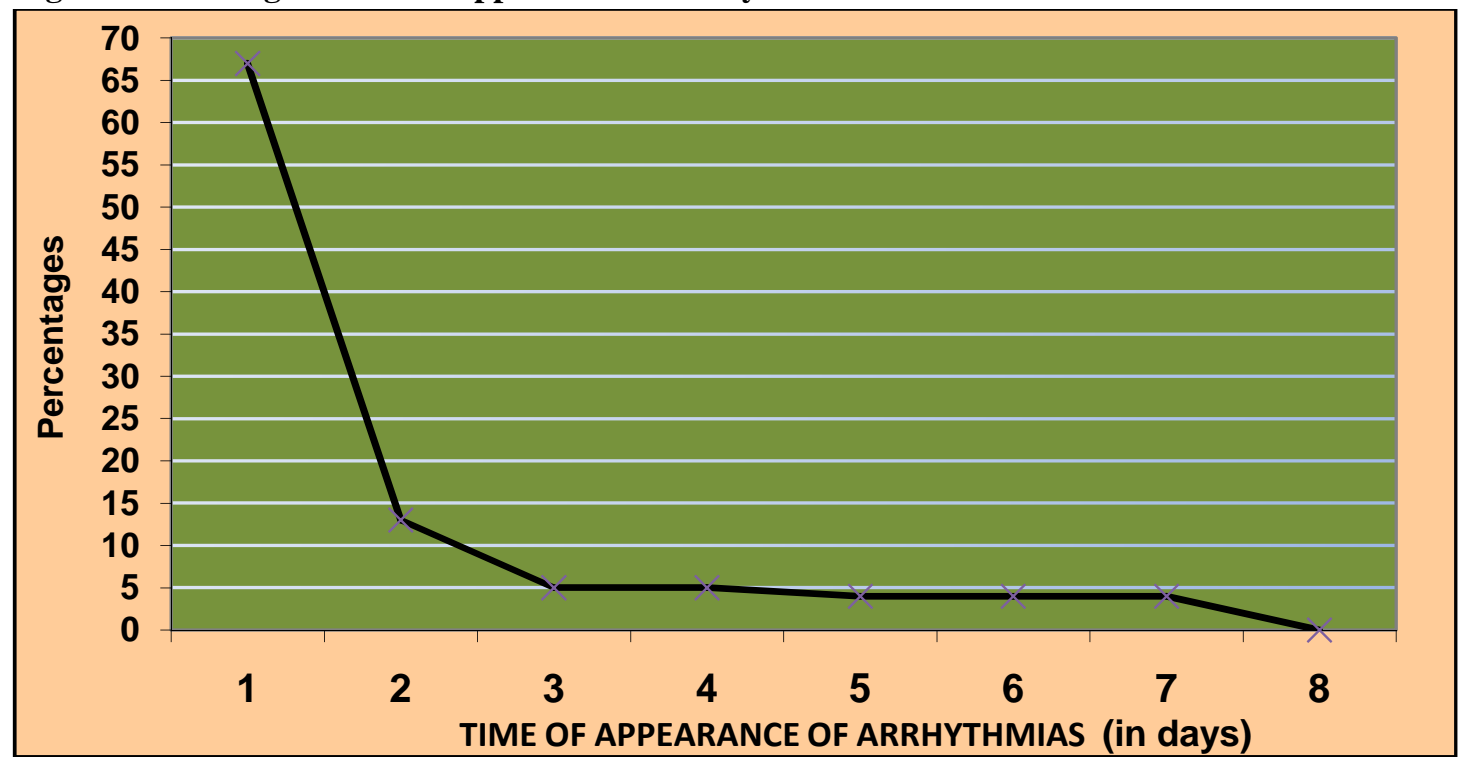

$67 \%$ of arrhythmias were documented within 24 hours of admission to ICCU, $13 \%$ between $25-48$ hrs, $5 \%$ between 49 $72 \mathrm{hrs}, 4 \%$ between $4^{\text {th }}$ to $7^{\text {th }}$ day and none after 1 week. 
Table 4: showing appearance of Individual arrhythmias after admission

\begin{tabular}{|l|l|l|l|l|l|l|l|l|l|}
\hline $\begin{array}{l}\text { Types of } \\
\text { arrhythmia }\end{array}$ & $\begin{array}{l}\mathbf{1}^{\text {st }} \\
\text { Day }\end{array}$ & $\begin{array}{l}\mathbf{2}^{\text {nd }} \\
\text { Day }\end{array}$ & $\begin{array}{l}\mathbf{3}^{\text {rd }} \\
\text { Day }\end{array}$ & $\begin{array}{l}\text { th } \\
\text { Day }\end{array}$ & $\begin{array}{l}\mathbf{5}^{\text {th }} \\
\text { Day }\end{array}$ & $\begin{array}{l}\mathbf{6}^{\text {th }} \\
\text { Day }\end{array}$ & $\begin{array}{l}\mathbf{7}^{\text {th }} \\
\text { Day }\end{array}$ & $\begin{array}{l}\text { After } \\
\mathbf{7} \\
\text { Days }\end{array}$ & Total \\
\hline $\begin{array}{l}\text { Sinus } \\
\text { tachycardia }\end{array}$ & 29 & 7 & 7 & 3 & 2 & - & - & - & 48 \\
\hline $\begin{array}{l}\text { Sinus } \\
\text { bradycardia }\end{array}$ & 15 & 2 & 1 & 1 & 1 & 1 & 1 & - & 22 \\
\hline APCs & 4 & 7 & 3 & - & - & 1 & - & - & 15 \\
\hline PAT & 1 & - & - & - & 1 & - & - & - & 2 \\
\hline AF & 2 & 2 & - & - & - & - & - & - & 4 \\
\hline SVT & 4 & 1 & - & - & - & - & - & - & 5 \\
\hline PJC & 1 & 1 & - & - & - & - & - & - & 2 \\
\hline $\begin{array}{l}\text { Nodal } \\
\text { rhythm }\end{array}$ & 3 & - & 1 & - & - & - & - & - & 4 \\
\hline VPC & 17 & 3 & 3 & 1 & - & - & - & - & 24 \\
\hline VT & 5 & 1 & - & - & - & - & - & - & 6 \\
\hline VF & 2 & 1 & - & - & - & - & - & - & 3 \\
\hline A V blocks & 10 & - & - & 1 & 1 & 2 & -- & - & 14 \\
\hline $\begin{array}{l}\text { Bundle } \\
\text { branch } \\
\text { Blocks }\end{array}$ & 10 & 1 & 1 & - & - & - & - & - & 12 \\
\hline
\end{tabular}

Sinus tachycardia was the commonest arrhythmia (48\%) followed by premature ventricular beats $(24 \%)$.

Table 5: showing incidence of various types of arrhythmia in relation to site of infarction

\begin{tabular}{|l|l|l|l|l|}
\hline Types of arrhythmia & Anterior wall MI & $\begin{array}{l}\text { Inferior wall } \\
\text { MI }\end{array}$ & $\begin{array}{l}\text { Combined } \\
\text { MI }\end{array}$ & Total (percentage) \\
\hline Sinus Tachycardia & $35(72.9 \%)$ & $11(22.9 \%)$ & $2(4.2 \%)$ & 48 \\
\hline Sinus Bradycardia & $10(45.4 \%)$ & $10(45.4 \%)$ & $2(9.1 \%)$ & 22 \\
\hline APCs & $13(86.7 \%)$ & $1(6.7 \%)$ & $1(6.7 \%)$ & 15 \\
\hline PAT & $2(100 \%)$ & 0 & 0 & 2 \\
\hline AF & $1(25 \%)$ & $3(75 \%)$ & 0 & 4 \\
\hline SVT & $4(80 \%)$ & $1(20 \%)$ & 0 & 5 \\
\hline PJC & 0 & $2(100 \%)$ & 0 & 2 \\
\hline Nodal rhythm & $2(50 \%)$ & $2(50 \%)$ & $2(8.3 \%)$ & 24 \\
\hline VPC & $17(70.8 \%)$ & $5(20.8 \%)$ & $2(8.3 \%)$ & 24 \\
\hline VT & $3(50 \%)$ & $3(50 \%)$ & 0 & 6 \\
\hline VF & $2(66.7 \%)$ & $1(33.3 \%)$ & 0 & 3 \\
\hline A V blocks & $1(7.1 \%)$ & $13(92.8 \%)$ & 0 & 14 \\
\hline Bundle branch blocks & $12(100 \%)$ & 0 & 0 & 12 \\
\hline
\end{tabular}

Atrioventrcular (Av) Blocks 
First degree AV block is seen in $5(5 \%)$, second degree AV block is seen in 5(5\%), of which Mobitz type $1 \&$ Mobitz type 2 are $3(3 \%) \& 2(2 \%)$ respectively, complete AV block is seen in 4(4\%) of patients. All the cases of AV blocks occurred in inferior wall MI except for one case of first degree AV block which occurred in anterior wall MI.

\section{Bundle Branch Blocks}

LAHB was present in $4(4 \%)$, RBBB in $2(2 \%), \mathrm{LBBB}$ in $1(1 \%)$ and RBBB+LAHB in $5(5 \%)$ of total cases. All the cases of bundle block were documented in anterior wall $\mathrm{MI}$.

\section{Discussion}

The age distribution of these patients ranged from 26 years to 84 years with maximum number of patients in the age group 41 to 50 years. This is consistent with findings of other authors who have quoted a similar incidence in this age group $[6,7,8,9,10]$. $22 \%$ of the patients were aged below 40years. This is comparable with study of Siwach et al [11] who have quoted an incidence of $19.2 \%$. There were 72 males (72\%) and 28 females $(28 \%)$ in the present study. The male to female ratio was 2.9:1. This findings is consistent with other studies $[6,7,8]$.

In our study incidence of arrhythmia was $89 \%$, the incidence of arrhythmia varies from 50-94 \% in various studies [6-8, 12-16]. The present findings are comparable with that of Sangitha Rathod et al [8], Kurland et al[12], Datey et al[14] and Jacob et al[16].

\section{Time of appearance of Arrhythmias}

67 patients $(67 \%)$ developed arrhythmias within 24 hours of admission while the remaining 22 patients (22\%) developed arrhythmia after 24 hours. 85 patients $(85 \%)$ had arrhythmias within 72 hours. This figure is slightly high compared to study of Mohit J Shah et al (2014)[7] who observed that $75 \%$ of arrhythmia's occurred within first 72 hours. The variation in incidence may be due to various factors like the method employed to pick up arrhythmias, monitoring of patient during early hours of AMI and the interval between onset of pain/symptoms and admission to hospital.

All patients received thrombolytic therapy. These patients demonstrated Premature ventricular beats $(30 \%)$, Accelerated idioventricular rhythm (10\%) and Sinus bradycardia $(5 \%)$ following thrombolysis. Since there is no facility for coronary angiography in our hospital, it could not be ascertained whether these arrhythmias were a consequence of coronary artery reperfusion or the evolution of infarct process itself.

\section{Sinus Tachycardia}

In our study incidence of sinus tachycardia was $48 \%$. It varies from 31-68 \% in various studies [8, 16-18]. Sinus Tachycardia was the commonest arrhythmia seen in this study. It was observed in 48 patients (48\%), which are comparable with studies of Julian et al [17] and Bahl et al [18].

\section{Sinus Bradycardia}

In our study incidence of sinus bradycardia was $22 \%$, the incidence of sinus bradycardia varies from 18-19.4 $\%$ in various studies $[8,16,19]$. The findings of present study are comparable to that of Jacob et al [16], Sloman et $\mathrm{al}[19]$ and Sangitha Rathod et al[8]. Sinus bradycardia occurred with equal frequency in anterior and inferior wall infarction $(4.4 \%$ each). This is in conformity with study of Rajgopalan et al[20], who observed it to occur with equal frequency in anterior and inferior infarction (50\%) each. 15 of the 22 patients $(68 \%)$ had developed sinus bradycardia within 24 hours of admission.

\section{Atrial Premature Contractions (APCs)}

In our study incidence of APC's was $15 \%$, the incidence of APC's varies from 4-16.3 \% in various studies [7, 8, 19-22]. The findings of present study are comparable to that of Jewitt et al[21], Sloman et al[19] and Subramanyam et al[22].

\section{Paroxysmal Atrial Tachycardia (PAT)}

In our study incidence of PAT was $2 \%$, the incidence of PAT varies from 1.2-3.92\% in various studies [22-27]. The findings of this study co-relate with studies of Aggarwal et al [23] and Raman et al [25].

\section{Atrial fibrillation}

In our study incidence of Atrial fibrillation was 4\%; the incidence of Atrial fibrillation varies from 1-5\% in various studies $[7,8,18,23,25]$. The finding are comparable to studies of Bahl et al [18], Aggarwal et al [23], Kudenchuck et al [28] and Mohit J Shah et al [7]. 
Atrial fibrillation was more frequent in inferior wall MI $(75 \%)$ than in anterior wall MI $(25 \%)$.

\section{Supraventricular Tachycardia (SVT)}

In our study incidence of SVT was 5\%; the incidence of SVT varies from $1-4.3 \%$ in various studies $[7,8,18$, 20, 29]. The findings are comparable to studies of Bahl et al [18] and Nigam et al [29].

\section{Premature Junctional Contractions (PJCs)}

In our study incidence of PJC's was $2 \%$; the incidence of PJC's varies from 2-4.9\% in various studies [24,25]. The findings are comparable with that of Raman et al [25].

\section{Junctional (Nodal) Rhythm}

In our study incidence of Junctional rhythm was 4\%; the incidence of Junctional rhythm varies from 1.3-7 \% in various studies [19, 21, 30]. The findings are comparable with the study of Sloman et al[19].

\section{Ventricular Premature Contractions (VPCs)}

In our study incidence of VPC's was $24 \%$. Incidence of VPC's varies from 21.56 - $56 \%$ in various studies [7, 8, $18,22,31-33]$. VPCs were the second most common arrhythmia documented in this study (24\%). This corelates with study of Bahl et al [18], Gupta et al [32] and Awadhi et al [33] and Subramanyam et al [22]. VPCs were more frequently documented in anterior wall MI $(70.8 \%)$ and occurred more frequently within first 24 hours $(70.8 \%)$. This is in concordance with the study of Sangitha Rathod et al [8] who have observed a higher incidence in anterior wall MI $(80 \%)$.

\section{Ventricular Tachycardia (VT)}

In our study incidence of VT was $6 \%$; the incidence of VT varies from 6 - $12 \%$ in various studies $[7,8,16,17$, $21,34]$. The findings of present study are comparable with that of Julian et al [17], Jewitt et a1[21], Jacob et al[16], Maggioni et al[34] and Sangitha Rathod et al [8]. Ventricular Tachycardia occurred with equal frequency in inferior and anterior infarction (50\% each). In 5 patients it occurred on the first day, in 1 patient on second day. In 2 patients Ventricular tachycardia rapidly degenerated into ventricular fibrillation and in 1 patient there is cardiogenic shock, all the 3 patients expired. 2 patients $(2 \%)$ had polymorphic ventricular tachycardia this co-Relates with findings of Wolfe et al (1991)[35] who have quoted an incidence of $2 \%$ for polymorphic VT in MI. Sustained ventricular tachycardia was seen in only 2 patients and other 4 patients had runs of unsustained ventricular tachycardia.

\section{Ventricular fibrillation}

In our study incidence of Ventricular fibrillation was $3 \%$; the incidence of Ventricular fibrillation varies from $2-6.5 \%$ in various studies $[7-9,16,24,33,36]$. The findings are comparable with study of kundu et al [24], Jacob et al[16] and Shimal Khan et al [9]. Two cases of ventricular fibrillation occurred in anterior wall Infarction $(66.7 \%)$ and one in inferior wall infarction $(33.3 \%)$. All three were cases of primary ventricular fibrillation as 2 patients Developed ventricular fibrillation on first day and 1 patient on second day. This incidence of primary Ventricular fibrillation (3\%) correlates with that of Volpi et al [37].

\section{Atrioventricular (AV) blocks First degree AV block}

In our study incidence of first degree $\mathrm{AV}$ block was $3 \%$; the incidence of first degree AV block varies from $2-6.5 \%$ in various studies $[7,8,12,19,20,23]$. The findings are comparable with study of Kurland et al [12], Rajgopalan et al[20] and Sangitha Rathod et al[8]. Of the 5 cases, 4 occurred in inferior wall $\mathrm{mi}(80 \%)$. This is comparable to study of Julian et al [17] who have observed it more frequently in inferior wall (77\%)

\section{Second degree AV block}

In our study incidence of second degree AV block was $6 \%$; the incidence of second degree AV block varies from $3.6-8.85 \%$ in various studies $[7,8,12,19,21$, 24]. The findings are comparable with study of Kurland et al[12], Sloman et al[19] and Sangitha Rathod et al[8]. All the cases of second degree AV block occurred in inferior wall MI. There were three cases $(60 \%)$ of Mobitz type I block and two cases (40\%) of Mobitz type II block.

\section{Third degree (Complete) AV block}

In our study incidence of complete heart block was $4 \%$; the incidence of complete heart block varies from $3.2-$ $6 \%$ in various studies [7-9, 15, 16, 21, 29, 30, 38-41]. The findings are comparable with studies of Imperial et al[30], Jewitt et al[21], Nigam et al[29], Jacob et al[16] and Shimal Khan et al[9]. All the four cases occurred in inferior wall MI and were documented within first 24 hours. 


\section{Bundle branch blocks}

In our study incidence of bundle branch blocks was $12 \%$; the incidence of bundle branch blocks varies from $10-21 \%$ in various studies [7, 16, 17, 21, 38, 42]. The findings are comparable with study of Julian et al[17], Chandrashekar et al[38] and Gupta et al[42]. All the cases of bundle branch blocks occurred in anterior wall MI.

\section{Left Anterior Hemiblock (LAHB)}

In our study incidence of LAHB was 5\%; the incidence of LAHB varies from 4.6-7.13\% in various studies [22, 38]. The findings are comparable with study of Chandrashekar et a $1[38]$.

\section{Right bundle branch block (RBBB)}

In our study incidence of RBBB was $2 \%$; the incidence of RBBB varies from 1.11-11\% in various studies [7, $18,29,38,40,43-45]$. The incidence of $\mathrm{RBBB}$ is comparable with those studies.

\section{Left Bundle Branch Block (LBBB)}

In our study incidence of $\mathrm{LBBB}$ was $1 \%$; the incidence of LBBB varies from $0.5-10 \%$ in various studies [7, 18, 29, 38, 40, 43, 45, 46]. The findings are comparable with study of Chandrashekar et al[38], Chatterjee et al[46] and Nair et al[43].

\section{Right Bundle Branch Block with Left Anterior hemiblock}

In our study incidence of RBBB+LAHB was $5 \%$; the incidence of $\mathrm{RBBB}+\mathrm{LAHB}$ varies from 2.6-6.2 \% in various studies [24, 38, 43, 44]. The findings are comparable with that of Kundu et $\mathrm{al}[24]$ and V. Balachandran[44].

\section{Relationship between Arrhythimias and Site of Infarction}

Arrhythmias occurred in $92.4 \%$ of the cases of anterior wall MIs, in other studies done by Sangitha Rathod et al[8], Murthy et al[47] it is $84.6 \& 88.5$ respectively, Arrhythmias in $83 \%$ cases of Inferior wall MIs, in other studies it varied between $60-74.6 \%$ and $75 \%$ of the cases of combined (anterior and inferior) MIs in other studies it varied from 54.6-83.3. These incidences are much higher than that of above studies. One reason is that, the overall incidence of arrhythmias in present study $(89 \%)$ is much higher than the above studies.

\section{Conclusion}

Arrhythmia continues to be the commonest complication of Acute Myocardial Infarction especially during first 48 hours. The variation in incidence may be due to various factors like the method employed to pick up arrhythmias, monitoring of patient during early hours of AMI and the interval between onset of symptoms and treatment, mode of treatment in hospital. Our observations confirmed the differences in the occurrence of arrhythmias in different setup and locality and need for individualization of management protocol in different setup.

\section{Funding: Nil \\ Conflict of interest: Nil \\ Permission from IRB: Yes}

\section{References}

1. Rissam HS, Kishore S, Trehan N. Coronary artery disease in young Indians: Journal Indian academy of clinical medicine. 2001July-Sept; 2(3):128-32.

2. Fabijanic D, Culic V, Bozic I et al. Gender differences in in-hospital mortality and mechanisms of death after the first acute myocardial infarction. Ann Saudi Med. 2006 Nov-Dec; 26(6):455-60.

3. Armstrong William F, and Paul L Mchenry. Ambulatory electrocardiographic monitoring: can we predict sudden death. J Am Coll Cardiol.1985 June; 5(6s1): 13B-6B.

4. Tunstall-Pedoe H. et al. Myocardial Infarction and coronary deaths in the World Health Organization MONICA Project. Circulation. 1994 July; 90(1): 583612.

5. Rowlands D.J. Clinical Electrocardiography, New York: Gower Medical Publishing. 1991;114-504.

6. PS Singh et al. Clinical profile and risk factors in acute coronary syndrome. Journal, Indian Academy of Clinical Medicine. 2013April-June; 14(2):130-2.

7. Mohit J Shah et al. A Study of 100 Cases of Arrhythmias in First Week of Acute Myocardial Infarction in Gujarat, A High Risk and Previously Undocumented Population. J Clin Diagn Res. 2014 Jan; 8(1): 58-61. 
8. Sangita Rathod et al. Study of various cardiac arrhythmias in patients of acute myocardial infarction: Int Arch Inte Med. 2014 December; 1(4): 32-41.

9. Shimal Khan et al. In-hospital outcome of patients having Acute myocardial infarction with and Without streptokinase; Gomal Journal of Medical Sciences. 2009 July-December; 7(2):96-100.

10. P. Yadav et al. clinical profile \& risk factors in acute coronary syndrome. National Journal of Community Medicine. 2010; 1(2):150-152.

11. Siwach S.B. et al. Profile of young acute myocardial infarction in Haryana. J Assoc Physicians India.1998 May; 46(5): 424-6.

12. Kurnald G.S. and D. Pressman. The incidence of arrhythmias in acute myocardial infarction studied with a constant monitoring system. Circulation. 1965 June; 31(6): 834-41.

13. Fluck D.C. et al. Natural history and clinical significance of arrhythmias after acute cardiac infarction. Br Heart J. 1967 March; 29(2):170-9.

14. Datey K.K. A.N. Nathwani and R.M. Shah. 100 Patients of acute myocardial infarction treated in an intensive coronary care unit. J Indian Med Assoc. 1969 May 1;52(9):405-9.

15. Sharma S.K. et al. Incidence and nature of cardiac arrhythmias in cases of acute myocardial infarction in relation to some major coronary risk factors. J Assoc Physicians India. 1986 Jun; 34(6):413-5.

16. Jacob et al. Study of incidence and pattern of arrhythmias complicating acute myocardial infarction correlating it to the site of infarct. Abstract: Joint Annual Conference of Association of Physicians of India and Cardiological Society of India: South Zone.1992;150-98.

17. Julian D.G, P.A. Valentine and G.C. Miller. Disturbances of Rate, Rhythm and conduction in acute myocardial infarction. Am.J. Me. 1964 December; 37(6): 915-27.

18. Bahl A. L., H.B. Lal and P.N. Dharwad. Arrhythmias complicating Acute myocardial infarction. J Indian Med Assoc. 1969 Dec 1;53(11):534-8.
19. Sloman G. and R.J. Prineas. Major Cardiac Arrhythmias in acute myocardial infarction: Implications for longterm survival. Chest 1973 April; 63(4): 513-6.

20. Rajgopalan et al. Acute cardiac infarction treated in an intensive coronary care unit. Indian Heart J. 1972 Apr;24(2):92-100.

21. Jewitt D.E. et al. Incidence and management of Supraventricular arrhythmias after acute myocardial infarction. Lancet.1967 October; 290(7519): 734-8.

22. Subramanyam G. and B. Ramesh Babu. Clinical profile of ischemic heart disease - A study of 2579 cases. J Assoc Physicians India. 1984 Jan;32(1): 48-9.

23. Aggarwal B.L. et al. Prognostic factors in Acute Myocardial infarction. Indian Heart J. 1978 JulAug;30(4):195-9.

24. Kundu S.C. et al. Profile of myocardial infarction among the Railroad workers in Eastern India - A six year study. Indian Heart J. 1982 May-Jun;34(3):151-5.

25. Raman R., V.R. Agarwal and A.K. Gupta. Incidence of atrial arrhythmias in cases of acute MI. J Assoc Physicians India. 1991 Nov;39(11):808.

26. Bandiera A. et al. Supraventricular hyperkinetic arrhythmias in acute myocardial infarct: their prognostic assessment and correlation with the echocardiographic evolution. Cardiologia. 1994 Sep;39(9):633-9.

27. Galcera T.J. et al. Incidence, clinical significance and prognostic significance of Supraventricular tachyarrhythmias in acute myocardial infarction. Rev Esp Cardiol. 1999 Sep;52(9):647-55.

28. Kudenchuk P.J. et al. Comparison of presentation, treatment and outcome of acute myocardial infarction in Men versus Women (The myocardial infarction triage and intervention registry). Am. J. Cardiol. 1996 July; 78(1): 9-14.

29. Nigam P.D. et al. Complications of acute myocardial infarction during first three weeks. Indian Heart J. 1968 Apr;20(2):157-64.

30. Imperial E.S, R. Carballo and H.A. Zimmerman. Disturbances of Rate, Rhythm and conduction in acute 
myocardial infarction. Am J. Cardiol.1960 January; 5(1):24-9.

31. Passey M.N. et al. Clinical profile of ischemic heart disease (Acute Myocardial Infarction). Indian Heart J. 1986 Jul-Aug;38(4) 334.

32. Gupta M.C, L. Mehta and S.P. Gupta. Clinical profile of acute myocardial infarction with special reference to risk factors - A five year study. J Assoc Physicians India. 1989 Jan;37(1) 55.

33. Awadhi A.H. et al. The prevalence and outcome of ventricular arrhythmias in acute myocardial infarction. Ir J Med Sci. 1990 Apr;159(4):101-3.

34. Maggioni A.P. et al. Prevalence and prognostic significance of ventricular arrhythmias after acute myocardial infarction in the fibrinolytic era. GISSI-2 Results. Circulation. 1993 February; 87(2): 312-22.

35. Wolfe C.L. et al. Polymorphous ventricular tachycardia associated with acute myocardial infarction. Circulation. 1991 October; 84(4): 1543-51.

36. Arun K.N. et al. Retrospective analysis of 500 cases of acute myocardial infarction. J Assoc Physicians India. $1989 \mathrm{Jan} ; 37(1): 11$.

37. Volpi A. et al. In-hospital prognosis of patients with acute myocardial infarction complicated by primary ventricular fibrillation. N. Engl. J. Med. 1987 July; 317(5): 257-61.

38. Chandrashekhara Rao A.S., S.T. Yavagal and D. Chinnaiah. Conduction disturbances in acute myocardial infarction. Indian Heart J. 1983 SepOct;35(5): 278.

39. Goldberg R.J. et al. Prognosis of acute myocardial infarction complicated by complete heart block (the
Worcester Heart Attach Study). Am J. Cardiol. 1992 May; 69(14): 1135-41.

40. Archbold R.A. et al. Frequency and prognostic implication of conduction defects in acute myocardial infarction since the introduction of thrombolytic therapy. Eur Heart J. 1998 Jun;19(6):893-8.

41. Harpaz D. et al. Complete atrioventricular block complicating acute myocardial infarction in the thrombolytic era, SPRINT study group and the Israel Thrombolytic survey group. J. Am. Coll. Cardiol. 1999 November; 34(6): 1721-8.

42. Gupta U.C. and M.L. Kataria. Prognostic significance of arrhythmias after acute myocardial infarction. J Assoc Physicians India. 1992 Dec;40(12):864.

43. Nair M. et al. Conduction disturbance in acute myocardial infarction, incidence and clinical significance. Indian Heart Journal. 1986 Sep-Oct;22 :405-9.

44. Balachandran V. Analysis of intraventricular conduction defects. J Assoc Physicians India. 1998 Jan;46(1) 102.

45. Sgarbossa E.B. et al. Acute myocardial infarction and complete bundle branch block at hospital admission: Clinical characteristics and outcome in the thrombolytic era GUSTO-I Investigations. J. Am. Coll. Cardiol. 1998 January; 31(1): 105-10.

46. Chatterjee S.S. et al. Acute myocardial infarction with conduction disorders. Indian Heart J. 1985 JulAug;37(4):238.

47. Murthy R.S.N. et al. Arrhythmias in acute myocardial infarction, incidence and clinical significance. Indian Heart J. 1984 Sep-Oct;36(5):335.

\section{How to cite this article?}

Nagabhushana S, Ranjith kumar GK, Ranganatha M, Virupakshappa. Study of Arrhythmias in Acute Myocardial Infarction. Int J Med Res Rev 2015;3(7):682-690. doi: 10.17511/ijmrr.2015.i7.126. 